\section{IJRDM 34,7}

\section{6}

\section{Online shopping portals: an option for traditional retailers?}

\author{
Aileen Kennedy and Joseph Coughlan
}

Faculty of Business, Dublin Institute of Technology, Dublin, Ireland

\begin{abstract}
Purpose - The purpose of the paper is to examine the benefits delivered to traditional retailers from using shopping portals as their entry mechanism to the online trading environment. The paper also aims to highlight the possible drawbacks inherent in such an approach.

Design/methodology/approach - A case study approach was used with an online portal, combining documentary analysis and semi-structured interviews, using a team-based interviewing approach. This facilitated the development of a multi-layered picture of the organisation.

Findings - Using a shopping portal delivers several benefits to traditional retailers in terms of marketing synergies, site traffic generation, access to web site management and fulfilment services, and the ability to offer customers a multi-channel retailing experience. Drawbacks may include partner interdependence and turnover, restricted organisational learning and restricted delivery capabilities.

Practical implications - Highlighting the benefits and drawbacks of shopping portals generates guidelines that traditional retailers can consider to help them decide whether such portals are the right choice for their individual firm or not.

Originality/value - This paper expands the literature on the phenomenon of the online portal by demonstrating its potential as a mechanism for traditional retailers to engage in electronic retailing.
\end{abstract}

Keywords Internet shopping, Portals, Electronic commerce, Retailing

Paper type Research paper

\title{
Introduction
}

Burt and Sparks (2003) suggest that we are witnessing the harnessing of the internet to enhance business efficiencies leading to the emergence of new formats within retailing. Such innovations have increased competitive pressures on traditional bricks and mortar store retailing (Dholakia and Uusitalo, 2002). Some commentators suggest that the future of shopping lies in multi-channel retailing (Dennis et al., 2002) where, rather than competing with the internet, retailers should incorporate it as part of their retail strategy, adopting a hybrid strategy combining both online and offline activity through a bricks and clicks approach. However, even established retailers recognise the difficulty inherent in "going it alone" in the transition to an online environment. One way of overcoming this difficulty is through joining an established online shopping portal which provides a support network through which to access this challenging environment.

The objective of this research is to investigate the benefits for traditional retailers of choosing this type of shopping portal as their vehicle to create an online presence. The paper begins with a discussion of electronic retailing and the pressures on organisations to move from "bricks and mortar" to "bricks and clicks". The important challenge of distribution is also highlighted. The qualitative research methodology is outlined. A brief overview of the case study organisation, Buy4Now[1], is then presented. The managerial implications of participation in the short- and medium-term are highlighted by examining both the benefits delivered to traditional retailers and

International Journal of Retail \& Distribution Management Vol. 34 No. 7, 2006 pp. $516-528$ (c) Emerald Group Publishing Limited 0959-0552

DOI $10.1108 / 09590550610673590$ 
also the drawbacks inherent in such an approach. Conclusions are drawn and suggestions for future research highlighted.

\section{Electronic retailing}

With the internet as a commercial medium, new ways of doing business have developed in almost every industry sector (Anckar et al., 2002) and retailing is no exception. This recent evolution has involved a shift towards non-store formats, especially through electronic means (Mulhern, 1997) opening up new perspectives on shopping in the future. Electronic retailing is currently the newest non-store retailing format, and while catalogue and TV shopping are fairly established within non-store retailing, shopping via the internet and www is new and emergent, representing the fastest growing segment within retailing (Dholakia and Uusitalo, 2002). Electronic retailing is the sale of products and services to the consumer market over the internet. It is also referred to variously as e-retailing, e-tailing and business to consumer (B2C) electronic commerce (e-commerce) (Kolesar and Galbraith, 2000).

Ellis-Chadwick et al. (2002) define the first stage of web retailing as the communication platform, where information on store location, product information, etc. is made available. Additionally interactive features are offered which may prompt the user to take some form of action, such as catalogue ordering or joining a mailing list (Scott et al., 2003). The second stage is defined as the electronic shop where retailers present their off-line shop online. The third and final stage is that of a trading community where retailers move beyond the e-shop model and develop or participate in portals, creating a shopping mall online (Scott et al., 2003).

\section{Converging retail models}

Stationary retailers or traditional bricks and mortar companies refer to organisations that have physical assets mainly in stores and distribution facilities (Kotzab and Madlberger, 2001). Innovations in non-store formats have increased competitive pressures on such traditional store retailing (Dholakia and Uusitalo, 2002). Recently electronic retailers have been attacking stationary retailers' market position. Dotcoms or virtual stores like Amazon.com have entered the market and taken serious market share from existing players. The basic characteristics of these virtual e-tailers are that they do not have any physical stores and market direct to consumers through the internet (Kotzab and Madlberger, 2001). As competition on the internet increases pure e-tailers have in turn come under increasing pressure to find new ways of attracting and retaining customers. Simultaneously traditional retailers have reached a point where they can no longer ignore the importance of online retailing and the exponential growth of e-tailers (Enders and Jelassi, 2000).

If conventional bricks and mortar shopping is threatened with losing substantial business to internet shopping, how should stationary retailers react competitively? Enders and Jelassi (2000) debate the converging business models of internet and bricks and mortar retailers suggesting that the emerging trend in the industry is the convergence of these two models of retailing. Dennis et al. (2002) concur that the future of shopping lies in multi-channel retailing where, rather than competing with the internet, retailers should adopt a hybrid strategy merging online and offline activities through a bricks and clicks approach. If retailers support traditional retail practices by engaging in e-commerce as a parallel strategy, they can provide customers 


\section{IJRDM 34,7}

518 with the opportunity to switch to internet-based shopping and easier delivery or to combine traditional and online shopping, depending on the products in question (Oinas, 2002). As both e-tailers and traditional retailers try to meet emerging market challenges by expanding their business models, for now it seems sensible for firms to design a multi-channel business model with multiple points of contact with the customer. This includes both a physical store and an online presence and in essence represents a hybrid format (Enders and Jelassi, 2000) or bricks and clicks approach. Otto and Chung (2000) refer to such a hybrid as cyber enhanced retailing, a paradigm melding the advantages of e-commerce with those of traditional physical retailing.

\section{Bricks and clicks approach}

Sharma and Sheth (2004) predict that customers will use the brick to click purchasing pattern, that is, they will buy on the internet from firms that have brick stores. These bricks and clicks combinations have both producer and customer-based advantages. Key producer advantages include prior customer bases and utilisation of established distribution and retail networks. Customer-based advantages include the reputation and trust already established by traditional retailers as well as consumer interest in the benefits offered by multi-channel shopping (Min and Wolfinbarger, 2005).

The bricks and mortar stores considering the transition to online operations have built in brand equity that can be leveraged on the web, and having a known brand lowers the cost of customer acquisition (Min and Wolfinbarger, 2005). It has been suggested that e-retailers that are part of traditional old economy companies will fare best, with stores that integrate e-tailing and a strong brand continuing to be successful (Dennis et al., 2002). Selling through existing physical stores and through internet channels allows retailers to leverage the strengths of each channel with stores and web sites working well together and so increasing sales at both (Chen and Leteney, 2000; Enders and Jelassi, 2000).

Additional advantages from integrating online and offline channels include increased shopping convenience, easier product return, and ability to offer information that may motivate a consumer to buy offline. Park et al. (2004, p. 13) suggest that "integrating online and offline operations may provide advantages such as broader distribution, reputation, management skills, and capital”. Bricks and clicks businesses can also augment their land-based businesses by offering customers extended selections online (Min and Wolfinbarger, 2005).

Hart et al. (2000) agree that retailers can add value to their existing operations by using the internet to extend their traditional product range, or by going one step further and linking with other related services, products, suppliers or retailers to provide the ultimate one-stop shop/collection point for customers. This has led to the development of sites acting as shopping centres online, which previous research has referred to as virtual malls (Hendershott et al., 2001) though the term portal is becoming more widely used (Ellis-Chadwick et al., 2002). If external network partners are relied on they tend to be specialists in web site building, maintenance and delivery (Oinas, 2002).

\section{Dealing with deliveries}

Retailers with online operations must deal with the delivery of products to end consumers. This complicated and expensive service is proving to be a challenging 
issue for online retailers (Kotzab and Madlberger, 2001). The critical issue is the need to fulfil logistic functions like picking, packing and transportation that are fulfilled free of charge by customers at physical stores. The management of these logistics emerges as a driving force for profitable e-tailing (Kotzab and Madlberger, 2001). However, many companies face difficulties delivering ordered goods and fulfilling the logistics function of their online operation. Doherty et al. (1999) suggest that many online orders are not delivered via a retailer-owned logistics network, but are instead outsourced to a third party. In some cases systems adaptation may involve the creation of a pick-up facility portals either at a store or some other point such as the workplace that would allow order consolidation and ensure that some of the logistics transportation cost is borne by the customer (Burt and Sparks, 2003). Geuens et al. (2002) also identify the fulfilment problem and the need for cheaper logistics and delivery, to make online shopping cheaper than in store shopping, as a crucial obstacle to overcome in the online environment. Customer loyalty and retention is also seen as the cornerstone of effective logistics, as the logistical costs of serving occasional customers needs is substantially higher than those of serving the continuous needs of permanent customers (Tanskanen et al., 2002).

\section{Research methodology}

The aim of the research was to explore the benefits and drawbacks for traditional retailers of choosing this type of online shopping portal as their vehicle to create an online presence. A case study approach was taken as it allowed both theory testing and development. This method has been suggested for research of this type in high technology environments (Brown and Eisenhardt, 1997; Johnston et al., 2000). A portal, Buy4Now[1], was chosen for the case study which facilitated the gathering of a rich picture of stationary retailers' experiences. Buy4Now was chosen as an exemplar of this channel because it had won an Irish Internet Association Net Visionary Award in 2003 for Online Trading[2]. At the time of conducting the research it was also well established with a wide range of retail partners covering diverse market segments, and was the sole online shopping portal in the Irish market. The use of this type of organisation for case study research is recommended by Eisenhardt (1989) as these organisations are exemplars of new developments and also offer the opportunity to test and extend current theories.

The research proceeded in three phases. Kaplan and Duchon (1988) argue that collecting different kinds of data by different methods from different sources provides a wider range of coverage that may result in a fuller picture of the unit under study than would have been achieved otherwise. First of all, a documentary analysis using offline and online sources was conducted on Buy4Now and the internet retailing industry in Ireland. Secondly, an analysis of internal operational documentation was carried out. Finally, semi-structured interviews with operational managers were undertaken following the approach of Barnes et al. (2004). Questions focused on understanding both the organisation itself and also its interactions with the retailers that form the portal. A team approach to interviewing was taken (Eisenhardt and Bourgeois, 1988) which improves the reliability of the study and builds confidence in the findings (Eisenhardt, 1989). The use of multiple sources of evidence, triangulation, enhances the reliability of findings and leads to a greater degree of belief in the accuracy of the findings (Yin, 1994). 


\section{IJRDM 34,7}

520

\section{Buy4Now: Ireland's online shopping portal}

Buy4Now was launched in October 2000 as an innovative virtual shopping portal offering Irish customers a fast, convenient and hassle free way of going shopping. The company adopted a clicks and mortar approach to online retailing combining well known and strongly branded Irish stores in one central location[1]. The Buy4Now shopping portal is based on the same premise as bricks and mortar shopping centres, an anchor tenant operates a large grocery store, in this case Superquinn, and other shops feed from that. Buy4Now was the first portal of its kind to take this approach in Europe.

The business model, unlike other e-tailing operations, is not based solely on transaction revenues[3]. Buy4Now also acts as an applications service provider (ASP), providing software fulfilment and hosting for its retail partners. When constructing the business model, management aimed for three revenue streams:

(1) Transaction percentage. All of the business within the portal results in Buy4Now receiving a percentage of the value of transactions.

(2) Advertising revenues. As with other portal sites Buy4Now seek to leverage its viewing numbers with advertising revenue.

(3) Recurring revenue. By handling the e-business strategies of some of Ireland's major retailers Buy4Now guarantees a source of recurring revenue for itself.

All partner sites come under the Buy4Now umbrella and use common software and design to enhance the customer experience. Buy4Now are the technology proprietors and are charged with expanding the functionality of the software over time which they have done through the development of in-store picking, order fulfilment, call centre and distribution software. With over two million products and 21 Irish stores trading online, traffic through the portal grew significantly in 2004 with over 100,000 visitors to the site each month and 2.2 million page impressions[4].

Retail partners include a department store (Arnotts), electrical outlet (discount electrical), book store (Eason), homecare/DIY outlet (Atlantic Homecare), sports shop (Elverys), computer outlet (Galaxy) florist and chemist among others[1]. The grocery anchor tenant is Superquinn. Service companies include a bank, hotel and mobile phone network operator. The total value of portal sales is predicted to reach $€ 20 \mathrm{~m}$ for 2005, up from $€ 15 \mathrm{~m}$ in 2004 (Anon, 2005a).

The portal harnesses the marketing and customer management techniques of the new economy while keeping its feet firmly entrenched in traditional retailing. Having well-established stores operate under the Buy4Now umbrella has meant that such bricks and mortar partnerships have put the company in a very different position to pure play dotcoms. It has positioned itself as a unique proposition in Ireland with real stores, strong retail partners and a centralized fulfilment solution. The company is currently in expansionary mode and hoping to take advantage of a much improved online climate.

\section{The partnering process}

Buy4Now is based around an ASP model where it manages web sites for its retail partners. It provides partner companies with usage licences and customisation work on their e-commerce sites, as well as providing portal functionality and marketing. In return the company charges a membership and usage/hosting fee. All retail partners 
to date have chosen to be fully integrated members of the Buy4Now portal using the companies own Shop4Now software engine[5]. Buy4now offers retailers exclusivity on the portal. Retailers have a written contract varying in length, averaging three years, with some partners opting for shorter terms. Contracts specify the percentage of the transaction value accruing to Buy4Now and the annual cost to the partner for usage licenses and web site customisation. A number of the partners also have equity stakes in the Buy4Now operation. Examples include Superquinn, the grocery partner, who portals own 11 per cent of the company and eircom, Ireland's largest telecommunications company, who own 22 per cent[6]. The philosophy of the organisation in choosing partners was summed up by the CEO "we went down a route initially of having a vision of creating a retail portal with quality Irish branded bricks and mortar retailers with a unique niche for each one and exclusive"[3].

\section{Logistics model}

Buy4Now's business is founded on the in-store picking model which means the company does not maintain a warehouse or inventory; instead its dedicated logistics teams collect goods directly from partner retailers. In 2002, Buy4Now moved into the logistics sphere after acquiring the assets of Irish fulfilment company ITS Logistics Ltd The purchase, made for $€ 600,000$, saw Buy4Now establish a new subsidiary Buy4Now Logistics Ltd to manage and co-ordinate the majority of the company's food and non-food deliveries, focusing on B2C delivery and primarily on internet deliveries[4].

\section{Portal participation and managerial implications for retailers}

The move to internet retail operations is shrouded in uncertainty for firms in terms of consumer demand, unproven business models, high costs of staying abreast with technology, a fragmented online market space and fierce competition for consumer traffic (Chatterjee, 2002). In this context even established retailers recognise the difficulty inherent in "going it alone". The network of the electronic medium makes it easier for retailers to develop their unique competencies and bring together, or borrow, resources and expertise from a wide range of partners, recognising the important role to be played by multi-firm structures (Chatterjee, 2002) such as the Buy4Now online shopping portal structure. In this case, technology provides the capability for a reconfiguration of existing business and channel relationships leading to the process innovation which is e-tailing (Burt and Sparks, 2003). This section examines the benefits delivered to retailers from using the Buy4Now portal as their entry mechanism to the online trading environment.

To begin with portal membership has facilitated retail partners' entry into a new market segment, an online shopping centre. Portal membership also offer partners the advantage of broader distribution and a new benefit in the online marketplace, that of increasing the installed base of customers (Park et al., 2004). Retailers also have easy access to information and to complementary resources. There are obvious cost advantages including customised software, centralised marketing and access to expertise and customers of other retail partners. These benefits are examined in more detail below. 


\section{IJRDM 34,7}

522

\section{Marketing synergies and advantages}

When shopping, consumers like to purchase groups of related products. Park et al. (2004) found increased value for the consumer when there was a mix of retailers being offered, as in an offline or online shopping centre format. A key benefit for retail partners on the Buy4Now portal is that consumers may visit the portal to purchase from one retailer but end up making additional unplanned purchases from a range of others. Retailers can therefore add value to their operations by linking with other related services, products and retailers to provide the ultimate one-stop shop/collection point for customers, which in turn helps drive traffic to the site. The Buy4Now model has operationalised this advantage for its retail partners.

The portal is built around interdependence and retail partners depend on full co-operation to generate portal traffic. The structure of the web site, with a central portal, facilitates this interdependency and there are additional synergistic benefits from a promotional perspective as if one partner promotes their company online or offline all members benefit from the spill over effect of such activity.

Based on UK retail research it has been suggested that this type of online platform or portal is currently only used by the most proactive web adopters, i.e. companies who have been using the web for transactions for at least the last three years (Ellis-Chadwick et al., 2002). For retailers partnering with Buy4Now this offers an opportunity to jump the learning curve in the online environment, as for the vast majority of retailers involved they have moved from no online activity to participation in a sophisticated and proactive online shopping portal in a matter of weeks not years. This is a crucial source of competitive advantage for these traditional retailers and their businesses.

\section{Generating site traffic}

Buy4Now has a strong anchor tenant in its grocery partner Superquinn. The success of the Tesco Direct model in Europe shows that food shopping on the internet is a winner and it is ideal for a portal site because the grocer creates regular traffic. As described by the Vice-President of Marketing:

... once customers have done two shops or more (grocery shopping) they are a customer for life because most people cannot face going back into the supermarket once they are used to getting it online[4].

This ability to generate regular site traffic is a key benefit accruing to partners as they join a portal with over 90,000 registered users, a large proportion of which are regular internet purchasers. Buy4Now also has plans to further invest in search engine marketing which should generate additional traffic for the portal and individual partners[5].

This is a huge benefit for retail partners as in addition to increased site traffic portal membership also generates access to potentially all of the customers of the other retail partners involved. As an additional benefit, partners have access to non-traditional online shoppers as Buy4Now visitor demographics are atypical mainly due to the prevalence of the mixed base of Superquinn grocery shoppers[5]. This has been described by the CEO of Buy4Now as the "classic win-win scenario" where retailers get their software and online presence from Buy4Now for less than they would pay for it elsewhere and they get footfall that is above and beyond their own URL[3]. 


\section{Brand leverage}

By enabling traditional well established retailers to outsource their online activities Buy4Now has achieved instant kudos as a place to shop. This overcomes a key challenge for both Buy4Now and its retail partners, that of encouraging consumers to modify their current shopping habits in favour of internet shopping (Kolesar and Galbraith, 2000), an area where few are succeeding. It has been suggested that stores who can integrate e-tailing and a strong brand will fare well (Dennis et al., 2002) and this has been the case with partners such as Superquinn, Arnotts, Eason and Appelby Jewellers who have established brand equity that can be leveraged on the web. In these cases having a known brand lowers the cost of customer acquisition for companies (Min and Wolfinbarger, 2005) and encourages loyal shoppers to make the transition online as the company does. This type of online shopping portal provides the online consumer with a range of services which are offered as a two way link passing traffic from one brand to another brand (Ellis-Chadwick et al., 2002).

Partners such as First Active bank seek different benefits from their association with the portal than retailers seeking additional sales. From their perspective a key benefit is association with premium retail brands. Through such brand association and brand leverage, smaller less well known organisations allied to Buy4Now can enjoy a halo effect in the eyes of the marketplace as posited by Stuart (2000).

\section{Customised web site management services}

Where retailers rely on external network partners in e-commerce activities they tend to be specialists in the technical side of the operation. This is reflected in the benefits for partners of their association with Buy4Now who offer a customised web site management service as well as marketing expertise.

The process of building web sites for partner companies has become simplified by the development of a standardised customisable content manager system by Buy4Now called Shop4Now[5]. A content manager system facilitates the updating of the partners' web sites by in-store staff by giving them online access to the development of their own site; allowing them to add new products, change prices, and amend the content of their own site. Partners take control of their own sites and those that sell physical products, as well as those who are pure online sellers, have to ensure that the system reflects product availability. Partners have to commit resources for their individual site to be successful and increasingly partner organisations are dedicating staff to manage their online presence[4]. Retailers can effectively test the market for their products on an incremental basis offering a low risk alternative to developing an independent online presence.

Buy4Now have developed their own order fulfilment system (OFS4Now) which allows retailers to view orders on their web sites[4]. Retailers receive orders and then pick the items from the shop floor. As the orders are filled they are updated on the system so that the customer can view their order status. Updates to the OFS4Now system link to the warehouse system operated by Buy4Now Logistics and to the Buy4Now portal and call centre system, allowing customer queries to be efficiently and effectively dealt with. The next stage is the Central Checkout Project which will allow integration of different retailers' products from a customer point of view[3]. 
$\mathrm{IJRDM}$ 34,7

524

\section{Providing a multi-channel shopping experience for customers}

Participation in the portal also allows partners to offer their customers the benefits of a multi-channel shopping experience (Min and Wolfinbarger, 2005). Where retailers support traditional practices with online activities, customers are provided with the opportunity to switch to internet-based shopping and easier delivery or to combine traditional and online shopping, depending on the products in question (Oinas, 2002). Additional advantages from integrating online and offline channels include increased shopping convenience, easier product return and the ability to offer information that may motivate a consumer to buy offline as suggested by the "brick to click" research of Sharma and Sheth (2004). Bricks and clicks businesses can also augment their land-based businesses by offering customers extended selections online (Min and Wolfinbarger, 2005) but in the case of Buy4Now retail partners have placed limited product selections online to date and need to expand the product assortment and depth to take full advantage of the medium[3]. As suggested by Hart et al. (2000) they should be adding value to their operations by using the internet to extend their traditional product range.

\section{Logistics and fulfilment services available to retailers}

The management of logistics has emerged as a driving force for profitable e-tailing (Kotzab and Madlberger, 2001) and as a crucial challenge for retailers who face difficulties fulfilling the logistics function of the online operation. Participating in the Buy4Now model alleviates this problem for partners as Buy4Now Logistics deals with the logistics and fulfilment side of the transactions. As highlighted by Doherty et al. (1999) Buy4Now Logistics becomes the bridge between customer ordering and delivery. Deliveries are made with Buy4Now branded vans. The establishment by Buy4Now of a dedicated logistics facility will support new delivery combinations and options for partners in the future including the planned Central Checkout program. Systems adaptation may involve the creation of a pick-up facility either at a store or some other point such as the workplace that would allow order consolidation and ensure that some of the logistics transportation cost is borne by the customer (Burt and Sparks, 2003). This is illustrated in the case of the anchor tenant Superquinn who launched a new service "Click and Collect" in 2003 (Clark, 2003) which allows shoppers to buy online and collect purchases at their convenience. The company described the new service as Ireland's first drive-through shopping facility.

As with any business development option available to firms there are drawbacks and opportunity costs involved in the choices made. The drawbacks of portal participation for existing and potential retail partners are discussed next.

\section{Strength of anchor tenant}

Any shopping centre is only as strong as its anchor tenant and the other retail outlets contained therein. In an online shopping portal model, such as Buy4Now, the anchor tenant is crucial to revenue and site traffic generation. In August 2005 the Superquinn chain was sold to Select Retail Holdings for €350m (Anon, 2005b) which is currently re-assessing all aspects of the business. Superquinn's involvement with the portal is likely to continue in some form as they are an original stakeholder in the company, but have also invested in parallel in their own uniquely positioned "Click and Collect" service for customers. Other grocery retailers in the marketplace, with the exception of 
the Tesco Direct model, have been slower to contemplate the integration of online shopping into their market offering. For retailers considering joining a portal as a strategy for going online, careful analysis of existing partners is crucial for success, especially in relation to the core tenant that drives the majority of the site traffic.

\section{Partner turnover}

The portal is built around partner interdependence and as partners change the overall offering is also altered. Partners who have not continued their association with the portal include Allied Irish Banks, who have a sophisticated corporate online presence developed within their own organisation, and Louis Copeland, providers of bespoke menswear whose product suitability to online sales was untested. As additional partners are added, for example 2005 saw the addition of Galaxy Computers, Play.com, and Sam McCauley chemist; site traffic must be divided among an increased number of retail partners' offerings. This may lessen the potential for brand leverage if the mix of partners does not complement the individual retailers brand positioning. Furthermore, Buy4Now offers partners exclusivity on the site. This is a significant advantage but may not be available from other portals of this type.

\section{Competition}

Originally Buy4Now was an innovative offering within the marketplace; five years later increased competition from French firm LeGuide[7], who have recently launched an online shopping portal specifically for Irish consumers, Shopwhale[8], may damage sales in the future. This new site has already signed up several well known Irish companies to customise the content for visitors. Although this competition increases the overall online market potential, it does entice customers to do their shopping elsewhere.

\section{Learning}

Retailers participating in these online shopping portals gain access to expertise for web site development and management. This may allow them to leapfrog the competition and is less risky and faster than developing an independent online transaction oriented presence. Unfortunately, it also restricts organisational learning and development of internal expertise in this key area for the retailer. These issues must be evaluated in the context of the firms overall online strategy in the medium and long-term.

\section{Delivery capabilities}

Access to fulfilment and logistic services has been a major benefit for retail partners to date. However, while internet shopping continues to grow within the marketplace, delivery networks are still believed to exclude a sizeable amount of the population from the online service. Superquinn's service is mainly Dublin centric and while Tesco, the largest online grocer in the world, claims to cover 80 per cent of the Irish market this coverage still needs to be improved on (Anon, 2004). It is therefore important for national or regional players to assess the delivery capabilities of such portals as lack of coverage and delivery capability in key geographic regions/markets could prove problematic. 
$\mathrm{IJRDM}$ 34,7

526

\section{Conclusion}

Changes in the retail environment due to the internet have important ramifications for retailers. The drive towards multi-channel retailing incorporating an online format puts pressure on individual retailers to make their products and service available in multiple formats to customers. Although it is apparent that the future for many firms lies in the adoption of a bricks and clicks approach, the question remains as to how best to do this.

Developing a presence on the internet is expensive and also fraught with challenges such as site development and fulfilment. A solution put forward by this research is that joining an established portal negates many of these concerns. It allows the rapid development of a significant online presence and offers a favourable business proposition to established retailers making the transition online. It facilitates a low risk entry mechanism giving access to complementary resources and competences for defined periods of time, effectively allowing retailers to test the market while offering their customers the benefits of the multi-channel experience.

Retailers need to consider the strategic implications of basing their web strategies on such portal participation in both the short- and long-term. The decision to use such portals as opposed to "going it alone" must be made in the context of the firms organisational and financial resources, product assortment, and crucially the predicted value of online sales to overall business performance.

This research concentrated on the shopping portal, Buy4Now, as the unit of analysis from which to develop insights for retail practitioners. Future research will concentrate on the experiences of both past and present partners in the shopping portal. With an increasing number of portals of this type coming on-stream in the Irish marketplace it will be interesting to monitor the dynamics of how the market evolves in the future.

\section{Notes}

1. www.buy4now.ie

2. www.iia.ie

3. Interview with CEO, January 2004.

4. Interview with Vice-President Marketing, January 2004.

5. Interview with Content Manager, January 2004.

6. Companies Registration Office Ireland www.cro.ie (accessed March 2004).

7. www.leguide.com

8. www.shopwhale.ie

\section{References}

Anckar, B., Walden, P. and Jelassi, T. (2002), "Creating customer value in online grocery shopping", International Journal of Retail \& Distribution Management, Vol. 30 No. 4, pp. 211-20.

Anon (2004), "Online grocery shopping take up affected", Retail Intelligence Newsletter, 21 September, available at: www.retailintelligence.ie/newsletter/

Anon (2005a), "Making a dotcom comeback ...", Sunday Tribune, 10 July. 
Anon (2005b), "Superquinn sale finalised", Business World Live News, 26 August, available at: http://factfinder.businessworld.ie

Barnes, D., Hinton, M. and Mieczkowska, S. (2004), "Managing the transition from bricks-and-mortar to clicks-and-mortar: a business process perspective", Knowledge Process Management, Vol. 11 No. 3, pp. 199-209.

Brown, S.L. and Eisenhardt, K.M. (1997), "The art of continuous change: linking complexity theory and time-paced evolution in relentlessly shifting organisations", Administrative Science Quarterly, Vol. 42, pp. 1-34.

Burt, S. and Sparks, L. (2003), "E-commerce and the retail process: a review", Lournal of Retailing and Consumer Services, Vol. 10, pp. 275-86.

Chatterjee, P. (2002), "Interfirm alliances in online retailing”, Journal of Business Research, Vol. 57, pp. 714-23.

Chen, S. and Leteney, F. (2000), "Get real! Managing the next stage of internet retail”, European Management Journal, Vol. 18 No. 5, pp. 519-28.

Clark, M. (2003), "Superquinn launches Click\&Collect”, 8 July, available at: www.electricnews. net/news

Dennis, C., Harris, L. and Sandhu, B. (2002), "From bricks to clicks: understanding the e-consumer", Qualitative Market Research: An International Iournal, Vol. 5 No. 4, pp. 281-90.

Dholakia, R.R. and Uusitalo, O. (2002), "Switching to electronic stores: consumer characteristics and the perception of shopping benefits", International Journal of Retail \& Distribution Management, Vol. 30 No. 10, pp. 459-69.

Doherty, N., Ellis-Chadwick, F. and Hart, C. (1999), "Cyber retailing in the UK: the potential of the internet as a retail channel", International Journal of Retail \& Distribution Management, Vol. 27 No. 1, pp. 22-36.

Eisenhardt, K. (1989), "Building theories from case study research", Academy of Management Review, Vol. 14 No. 4, pp. 532-50.

Eisenhardt, K. and Bourgeois, L.J. (1988), "Politics of strategic decision making in high velocity environments. Toward a mid range theory", Academv of Management Iournal, Vol. 31, pp. 737-70.

Ellis-Chadwick, F., Doherty, N. and Hart, K. (2002), "Signs of change? A longitudinal study of internet adoption in the UK retail sector", Journal of Retailing and Consumer Services, Vol. 9, pp. 71-80.

Enders, A. and Jelassi, T. (2000), "The converging business models of internet bricks and clicks retailers", Eurobean Management Journal, Vol. 18 No. 5, pp. 542-50.

Geuens, M., Brengman, M. and S'Jegers, R. (2003), "Food retailing, now and in the future. A consumer perspective", Journal of Retailing and Consumer Services, Vol. 10, pp. 241-51.

Hart, C., Doherty, N. and Ellis-Chadwick, F. (2000), "Retailer adoption of the internet: implications for retail marketing", European Iournal of Marketing, Vol. 34 No. 8, pp. 954-74.

Hendershott, P.H., Hendershott, R.J. and Hendershott, T.J. (2001), "The future of virtual malls", Real Estate Finance, Vol. 18 No. 1, pp. 25-32.

Johnston, W.J., Leach, M.P. and Liu, A.M. (2000), "Using case studies for theory testing in business-to-business research: the development of a more rigorous case study methodology", Advances in Business Marketing and Purchasing, Vol. 9, pp. 215-41.

Kaplan, B. and Duchon, D. (1988), "Combining qualitative and quantitative research methods in information systems research: a case study”, MIS Quarterlv, Vol. 12 No. 4, pp. 571-86. 
$\mathrm{IJRDM}$ 34,7

528
Kolesar, M.B. and Galbraith, R.W. (2000), "A services-marketing perspective on e-tailing: implications for e-tailers and directions for future research", Internet Research: Electronic Networking Aphlications and Policy, Vol. 10 No. 5, pp. 424-38.

Kotzab, M. and Madlberger, M. (2001), "European retailing in e-transition? An empirical evaluation of web-based retailing - indications from Austria", International Iournal of Physical Distribution \& Logistics Management, Vol. 31 No. 6, pp. 440-62.

Min, S. and Wolfinbarger, M. (2005), "Market share, profit margin and marketing efficiency of early movers, bricks and clicks, and specialists in e-commerce", Lournal of Business Research, Vol. 58, pp. 1030-9.

Mulhern, F.J. (1997), "Retail marketing: from distribution to integration", International Journal of Research in Marketing, Vol. 14, pp. 3-24.

Oinas, P. (2002), "Towards understanding network relationships in online retailing", International Review of Retail, Distribution \& Consumer Research, Vol. 12 No. 3, pp. 319-35.

Otto, J.R. and Chung, Q.B. (2000), "A framework for cyber-enhanced retailing: integrating e-commerce retailing with brick and mortar retailing”, Electronic Markets, Vol. 10 No. 3, pp. 185-91.

Park, N.K., Mexias, J.M. and Song, J. (2004), “A resource-based view of strategic alliances and firm value in the electronic marketplace", Lournal of Management, Vol. 30 No. 1, pp. 7-27.

Scott, M., Golden, W. and Hughes, M. (2003), "E-tailing in Ireland: a review of Ireland's top 25 retailers", Irish Marketing Review, Vol. 16 No. 1, pp. 15-24.

Sharma, A. and Sheth, J.N. (2004), "Web-based marketing: the coming revolution in marketing thought and strategy", Lournal of Business Research, Vol. 57, pp. 696-702.

Stuart, T.E. (2000), "Interorganizational alliances and the performance of firms: a study of growth and innovation rates in a high-technology industry", Strategic Management Journal, Vol. 21 No. 8, pp. 791-811.

Tanskanen, K., Yrjölä, H. and Holström, J. (2002), "The way to profitable internet grocery retailing - six lessons learned", International Iournal of Retail \& Distribution Management, Vol. 30 No. 4, pp. 169-78.

Yin, R.K. (1994), Case Study Research: Design and Methods, Sage, London.

Corresponding author

Aileen Kennedy can be contacted at: aileen.kennedy@dit.ie

To purchase reprints of this article please e-mail: reprints@emeraldinsight.com Or visit our web site for further details: www.emeraldinsight.com/reprints 
This article has been cited by:

1. Mirjana Pejic-Bach, Blazenka Knezevic, Miran Pejic-Bach. 2012. Development of a Web Based Business Oriented Towards a Market Niche in an Emerging Economy. Journal of Cases on Information Technology 12:10.4018/jcit.20100401, 31-48. [CrossRef]

2. Catherine J. Ashworth. 2012. Marketing and organisational development in e-SMEs: understanding survival and sustainability in growth-oriented and comfort-zone pure-play enterprises in the fashion retail industry. International Entrepreneurship and Management Journal 8, 165-201. [CrossRef]

3. Roger Bennett, Sharmila Savani. 2011. Retailers' preparedness for the introduction of third wave (ubiquitous) computing applications. International Journal of Retail \& Distribution Management 39:5, 306-325. [Abstract] [Full Text] [PDF] 